\title{
Transformation from Rod-like to Diamond-like Micelles by Thermally Induced Nucleation Self-assembly
}

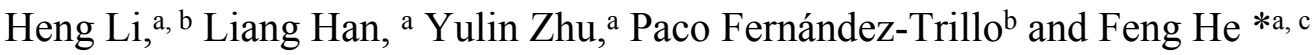

a Shenzhen Grubbs Institute and Department of Chemistry, Southern University of Science and Technology, Shenzhen, 518055, China.

b School of Chemistry, University of Birmingham, B15 2TT, UK.

${ }^{\mathrm{c}}$ Guangdong Provincial Key Laboratory of Catalysis, Southern University of Science and Technology, Shenzhen, 518055, China

Corresponding author. E-mail: hef@sustech.edu.cn (F.H.). 


\section{Supplementary Methods}

\section{Experimental Methods}

Materials. Most of reagents and solutions were used as commercially received in synthesized procedures except dimethylformamide $(\mathrm{DMF})$, potassium tert-butoxide $(\mathrm{K} t \mathrm{BuO})$, 1,1-diphenylethlene (DPE), 2-vinylpyridine (2VP), lithium chloride ( $\mathrm{LiCl}$ ), tetrahydrofuran (THF) and benzene. DMF was dried with molecular sieve before used. $\mathrm{Kt} \mathrm{BuO}$ and $\mathrm{LiCl}$ were heated at $120{ }^{\circ} \mathrm{C}$ under vacuum to remove water. DPE was titrated with n-BuLi until a red color sustained and then distilled under reduced pressure. 2VP was distilled with $\mathrm{CaH}_{2}$ twice. THF and benzene was dried with $\mathrm{Na}$ and used as freshly distilled.

Characterization Equipment. ${ }^{1} \mathrm{H}$ NMR spectra were measured on a Bruker AVANCE $400 \mathrm{MHz}$ spectrometer with tetramethylsilane (TMS) as the internal standard. Molecular weights were determined by GPC measurements, which were carried out on a Waters ACQUITY APC System equipped with a UV detector (Waters ACQUITY TUV) and 3 series connected chromatographic columns (ACQUITY APC XT 450, 200, 45, $4.6 \times 150 \mathrm{~mm}$ ). Polystyrene standards (Aldrich) were used for calibration, and THF was used as the eluent with a flow rate of $0.5 \mathrm{ml} \mathrm{min}^{-1}$ at $40{ }^{\circ} \mathrm{C}$. Matrix-assisted laser desorption/ ionization time of flight mass spectrometry (MOLDI-TOF) mass spectrum were obtained on a Waters MICROMASS MALDI-TOF micro MX Mass Spectrometer. Small aliquots of sample solution $(2 \mu \mathrm{L}$, $1.0 \mathrm{mg} \mathrm{mL}^{-1}$ ) in chloroform were added to a sample plate for MOLDI-TOF. After drying in air at room temperature (about $10 \mathrm{~min}$ ), an aliquot of $\alpha$-cyano-4-hydroxy cinnamic acid $\left(2 \mu \mathrm{L}, 5.0 \mathrm{mg} \mathrm{mL}^{-1}\right)$ dispersed in a mixture of acetonitrile and water (acetonitrile/water $=1 / 1$ ) was added and allowed to dry in air at room temperature.

Transmission electron microscopy. Transmission electron microscopy (TEM) photographs were taken by using a Hitachi HT7700 TEM instrument and operating at $100 \mathrm{kV}$. The samples were prepared by putting a drop of solution of assemblies on carbon-coated copper grids followed by solvent evaporated. For the statistical analysis, the achieved photos were analyzed by using Digital Micrograph software package developed by the US Gatan company. $\mathrm{L}_{\mathrm{n}}$ is the number-average length and $\mathrm{L}_{\mathrm{w}}$ is the 
weight-average length of $1 \mathrm{D}$ rod-like micelles, which were determined form the statistics of the length of 100 rod-like micelles with equation S1 and S2. The longer diagonal length was calculated to characterize the scale of the 2D diamond micelles. 100 2D diamond micelles from TEM images were traced by hand. $D_{l n}$ (number-average length of the longer diagonal) and $D_{l w}$ (weight-average length of the longer diagonal) of each sample of 2D diamond micelles were determined from these data by using equations S3 and S4, respectively (where $D_{1}$ is the longer diagonal length of individual platelet 2D diamond micelles, $N_{\mathrm{i}}$ is the number of longer diagonal length).

$$
\begin{gathered}
L_{\mathrm{n}}=\frac{\sum_{\mathrm{i}=1}^{N} N_{\mathrm{i}} L_{\mathrm{i}}}{\sum_{\mathrm{i}=1}^{N} N_{\mathrm{i}}} \\
L_{\mathrm{w}}=\frac{\sum_{\mathrm{i}=1}^{N} N_{\mathrm{i}} L_{\mathrm{i}}^{2}}{\sum_{\mathrm{i}=1}^{N} N_{\mathrm{i}} L_{\mathrm{i}}} \\
D_{\mathrm{ln}}=\frac{\sum_{\mathrm{i}=1}^{N} N_{\mathrm{i}} D_{\mathrm{li}}}{\sum_{\mathrm{i}=1}^{N} N_{\mathrm{i}}} \\
D_{\mathrm{lw}}=\frac{\sum_{\mathrm{i}=1}^{N} N_{\mathrm{i}} D_{\mathrm{li}}^{2}}{\sum_{\mathrm{i}=1}^{N} N_{\mathrm{i}} D_{\mathrm{li}}}
\end{gathered}
$$

Atomic force microscopy. The detected AFM samples were prepared by drop-coating about $15 \mu \mathrm{L}$ of the 2-D assemblies' solution onto a pre-cleaned and treated silicon wafer followed by evaporating the solvent isobutanol. The silicon wafers used as substrate were cleaned in piranha solution for $6 \mathrm{~h}$, then ultrasound treated in ethanol, water, and ultrapure water in turn, and finally dried with blowing nitrogen. The images were gained using an Asylum Research AFM in AC mode under ambient conditions. The used sensor cantilevers were Silicon probe reflex coated with aluminum manufactured by Budget sensors Company. Images were analyzed with IGOR Pro software developed by WaveMetrics Inc.

UV-Vis Absorption Spectra (UV-Vis). The PL spectra were recorded by a Shimadzu RF6000 spectrofluorometer. The samples were prepared by dissolving $\left(\mathrm{PPV}-\mathrm{Cl}_{20}\right)_{10}-b-\mathrm{P} 2 \mathrm{VP} 20$ in isobutanol 
under a concentration of $0.01 \mathrm{mg} \mathrm{ml}^{-1}$ and the prepared isobutanol solutions were heated at $90{ }^{\circ} \mathrm{C}$ for $1 \mathrm{~h}$, cooled to room temperature $\left(25^{\circ} \mathrm{C}\right)$, and aged for $24 \mathrm{~h}$.

Grazing Incidence Wide-angle X-ray Scattering (GIWAXS). The samples were prepared by dropcoating $60 \mu \mathrm{l}$ of the solution onto the pre-cleaned and treated silicon wafer followed by evaporating the solvent for seven times. The silicon wafers were cleaned in piranha solution for $30 \mathrm{~min}$, then ultrasound successively in ethanol, ultrapure water, and finally dried with blowing nitrogen dispersed.

Dynamic light scattering. Dynamic light scattering (DLS) measurements were performed by using a Brookhaven NanoBrook Omni laser light-scattering apparatus with a $635 \mathrm{~nm}$ red laser. The isobutanol solution of $\left(\mathrm{PPV}-\mathrm{Cl}_{20} \%\right)_{10}-b-\mathrm{P} 2 \mathrm{VP}_{20}$ was heated at $90{ }^{\circ} \mathrm{C}$ for $1 \mathrm{~h}$ and then spontaneously cooled to room temperature. After the sample solution was cooled to room temperature, the DLS was measured at $1 \mathrm{~h}$, $3 \mathrm{~h}$ until aging for $24 \mathrm{~h}$. On the other hand, the self-assembly sample was measured every day until 7 days.

Differential scanning calorimetry. Different scanning calorimetry (DSC) measurements were performed on a Discovery series thermal analyzer at a scanning rate of $10{ }^{\circ} \mathrm{C} \mathrm{min}^{-1}$ in $\mathrm{N}_{2}$ atmosphere. The samples were heated from 30 to $150{ }^{\circ} \mathrm{C}$, and then cooled back to $30^{\circ} \mathrm{C}$. The thermal cycles carried on twice, and the data of second cycle were used to analyze. 


\section{Polymer Synthesis and Characterization.}

All of air- or moisture-sensitive reactions were carried out in dried glassware under an argon pressure using Schlenk techniques or in a glove box under nitrogen atmosphere. The detailed procedure path of synthesis was illustrated in scheme S1 and S2.

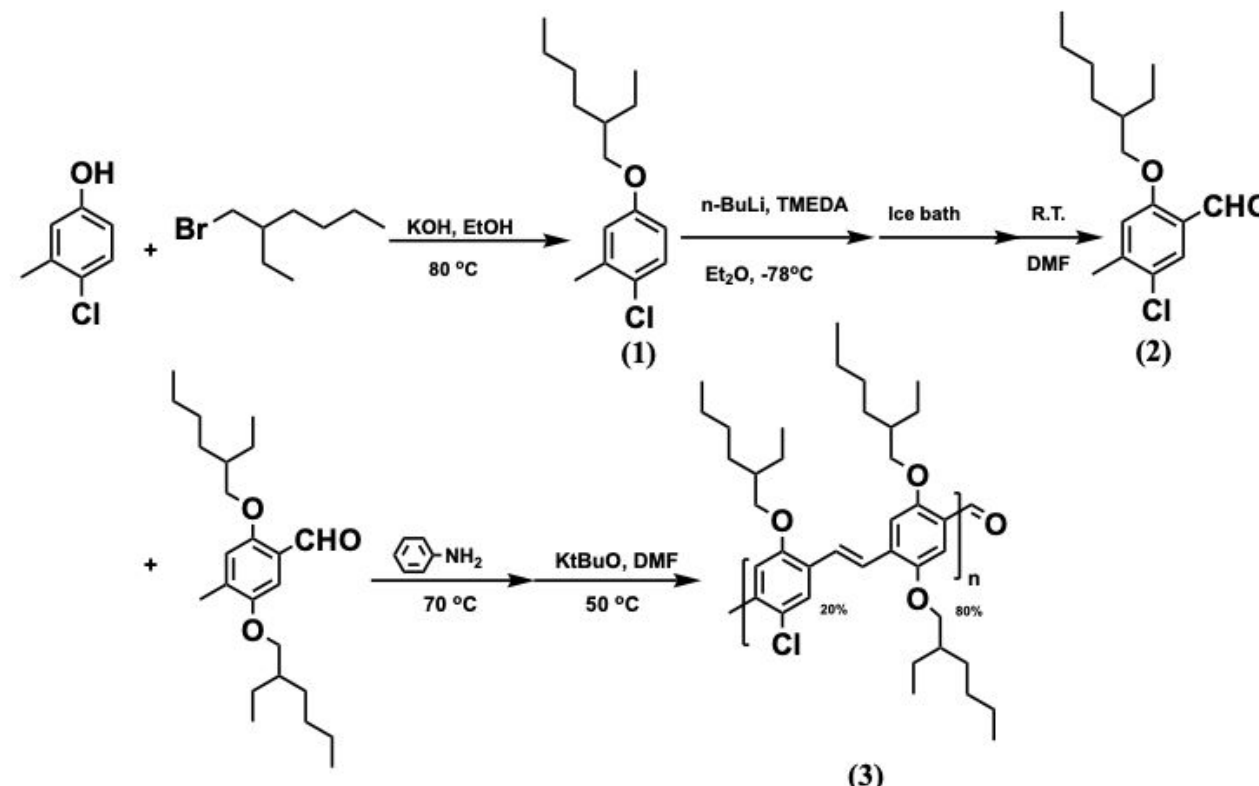

(3)

Scheme S1 Synthesis route of (PPV-Cl $\left.{ }_{20} \%\right)_{10^{-}}$CHO.

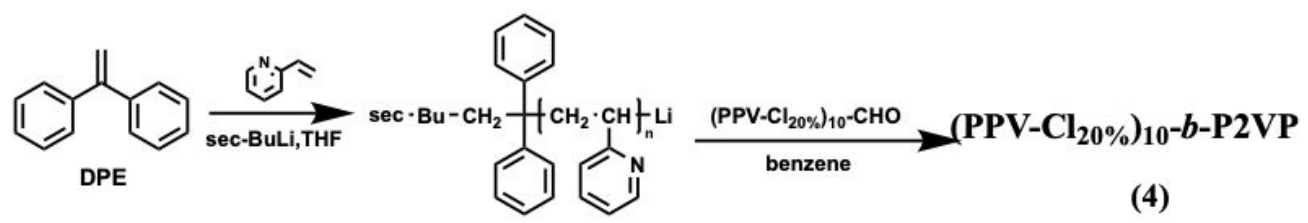

Scheme S2 Synthesis route for $\left(\mathrm{PPV}-\mathrm{Cl}_{20}\right)_{10}-b-\mathrm{P} 2 \mathrm{VP}_{20}$.

Synthesis of 1-chloro-4-((2-ethylhexyl) oxy)-2-methylbenzene (1). A mixture of 4-chloro-3methylphenol $(14.2 \mathrm{~g}, 0.1 \mathrm{~mol})$ and $\mathrm{KOH}(16.42 \mathrm{~g}, 0.29 \mathrm{~mol})$ in ethanol $(170 \mathrm{~mL})$ was refluxed at $80{ }^{\circ} \mathrm{C}$ for $1 \mathrm{~h}$ under Ar atmosphere. After that, 3-(bromomethyl) heptane $(52 \mathrm{~mL}, 0.29 \mathrm{~mol})$ was added to the stirring refluxing solution. The reaction was refluxed overnight. After cooling to room temperature, 700 $\mathrm{mL}$ water was added into mixture. The mixture was extracted with anhydrous ethyl acetate $(3 \times 100$ 
$\mathrm{mL}$ ), then the gathered organic phase was dried with $\mathrm{MgSO}_{4}$, finally the solvent was removed by rotary evaporator. After purification by chromatography (silica gel, $\mathrm{CH}_{2} \mathrm{Cl}_{2}$ / petroleum ether 1:10), a yellow oil (1, $19.8 \mathrm{~g}, 0.078 \mathrm{~mol}, 77.89 \%)$ was obtained. ${ }^{1} \mathrm{H}$ NMR $\left(400 \mathrm{MHz}, \mathrm{CD}_{2} \mathrm{Cl}_{2}\right): \delta 7.26-7.20(\mathrm{~d}, 1 \mathrm{H})$, $6.75(\mathrm{~s}, 1 \mathrm{H}), 6.65-6.62(\mathrm{~d}, 1 \mathrm{H}), 3.80-3.75(\mathrm{~m}, 2 \mathrm{H}), 2.31(\mathrm{~s}, 3 \mathrm{H}), 1.71-1.69(\mathrm{~m}, 1 \mathrm{H}), 1.61-1.48(\mathrm{~m}, 4 \mathrm{H})$ 1.36-1.24 (m, 4H), 0.98-0.92 (m, 6H).

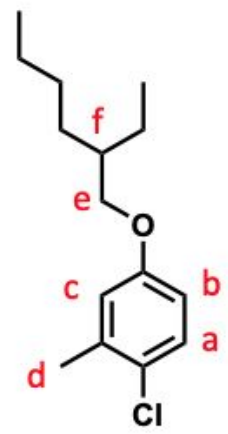

\author{
(1)
}


was purified by chromatography (silica gel, $\mathrm{CH}_{2} \mathrm{Cl}_{2}$ : petroleum ether $\left.1: 7\right)$, a yellow oil $(2,1.12 \mathrm{~g}, 3.95$ mmol, 79\%) was obtained. 2,5-bis(2-ethylhexyloxy)-4-methylbenzaldehyde was synthesized by reported procedure. ${ }^{[1]}{ }^{1} \mathrm{H}$ NMR $\left(400 \mathrm{MHz}, \mathrm{CDCl}_{3}\right): \delta 10.43(\mathrm{~s}, 1 \mathrm{H}), 7.76(\mathrm{~s}, 1 \mathrm{H}), 6.68(\mathrm{~s}, 1 \mathrm{H}), 3.92(\mathrm{~d}$, 2H), $2.43(\mathrm{~s}, 3 \mathrm{H}), 1.84-1.79(\mathrm{~m}, 1 \mathrm{H}), 0.97-0.87(\mathrm{~m}, 6 \mathrm{H})$.

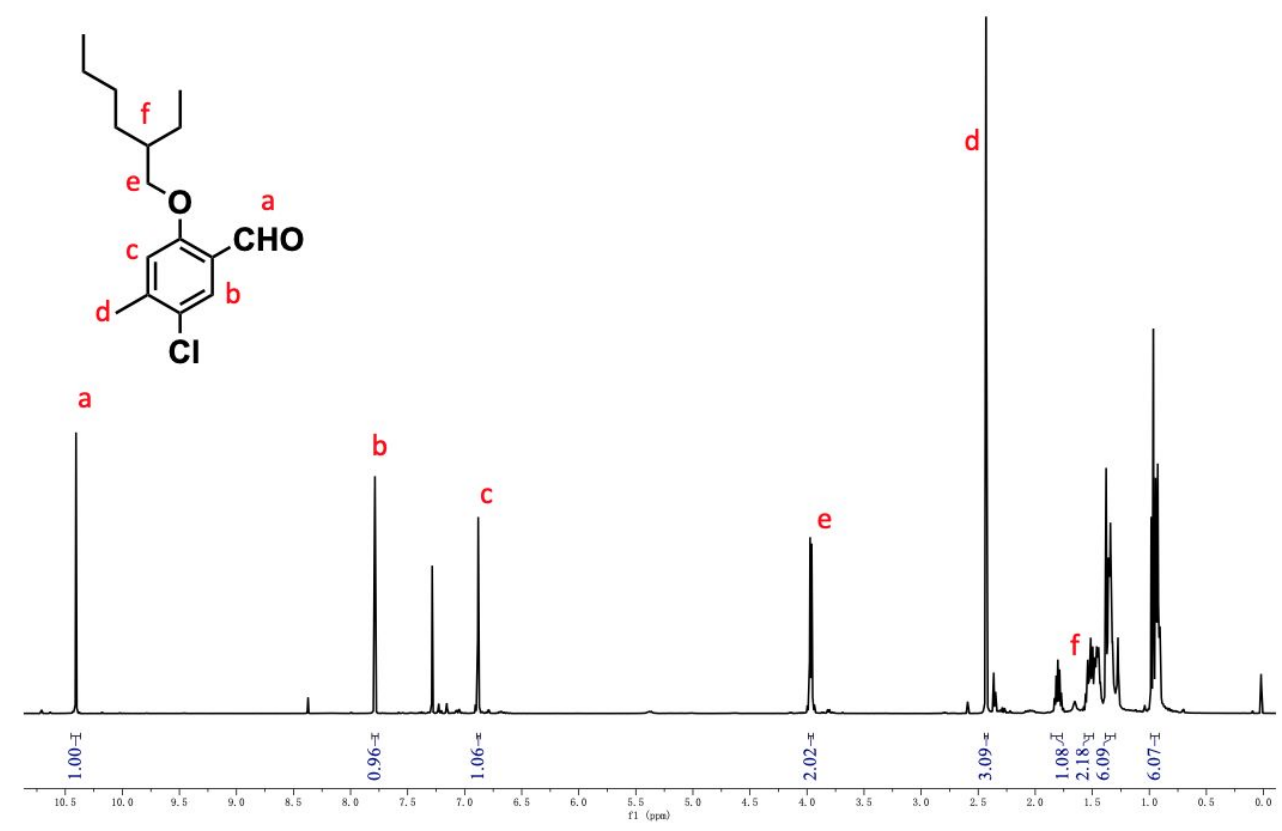

Figure S2 ${ }^{1} \mathrm{H}$ NMR spectrum of 5-chloro-2-((2-ethylhexyl) oxy)-4-methylbenzaldehyde in $\mathrm{CDCl}_{3}$.

\section{Synthesis of Poly-4-(5-chloro-2-((2-ethylhexyl) oxy)-4-methylstyryl)-2,5-bis((2-ethylhexyl) oxy))-} benzaldehyde (PPV-Cl $\left.{ }_{20 \%}-\mathrm{CHO}\right) \quad$ (3). A mixture of 5-chloro-2-((2-ethylhexyl)oxy)-4methylbenzaldehyde (compound $\quad \mathbf{2}, \quad 1.12 \quad \mathrm{~g}, \quad 3.95 \quad \mathrm{mmol}$ ), 2,5-bis(2-ethylhexyloxy)-4methylbenzaldehyde ( $5.94 \mathrm{~g}, 15.8 \mathrm{mmol})$ and aniline $(6.16 \mathrm{~g}, 66.06 \mathrm{mmol})$ was stirred for $2 \mathrm{~h}$ at $50{ }^{\circ} \mathrm{C}$ under reduced pressure, then the temperature of the mixture raised to $110{ }^{\circ} \mathrm{C}$ to remove excess aniline. The yielded deep yellow viscous oil. Next, the solution of yellow oil in $40 \mathrm{~mL}$ anhydrous DMF was added into round flask containing potassium tert-butoxide $(2.25 \mathrm{~g}, 30 \mathrm{mmol})$ with $250 \mathrm{~mL}$ anhydrous $\mathrm{DMF}$ at $50{ }^{\circ} \mathrm{C}$. After stirring for $1 \mathrm{~h}$ at the same temperature, the mixture was poured into $250 \mathrm{~mL} 1 \mathrm{M}$ hydrochloric acid and stirred for $48 \mathrm{~h}$. Then the reaction mixture was extracted with chloroform $(3 \times 10$ $\mathrm{mL}$ ), and the organic phase was successively washed by aqueous $\mathrm{NaHCO}_{3}$ and water followed by dried 
with $\mathrm{MgSO}_{4}$ and rotary evaporating. Product in low dispersity was successively collected and fractionated by methanol, acetone and hexane with Soxhlet extraction. The number-average degree of polymerization $\mathrm{n}=10$ for PPV-Cl ${ }_{20 \%}-\mathrm{CHO}$ was determined by ${ }^{1} \mathrm{H}$ NMR and mass. The polydispersity index was measured at 1.12 by GPC in THF. ${ }^{1} \mathrm{H}$ NMR (400 MHz, $\left.\mathrm{CDCl}_{3}\right): \delta 10.46(\mathrm{~s}, 1 \mathrm{H}), 7.69-7.52$ (m, 22H), 7.35-7.19 (m, 16H), 4.09-3.81 (m, 36H), $2.14(\mathrm{~s}, 3 \mathrm{H}), 2.05-1.98(\mathrm{~m}), 1.65-1.23(\mathrm{~m}), 1.09-$ $0.81(\mathrm{~m})$.

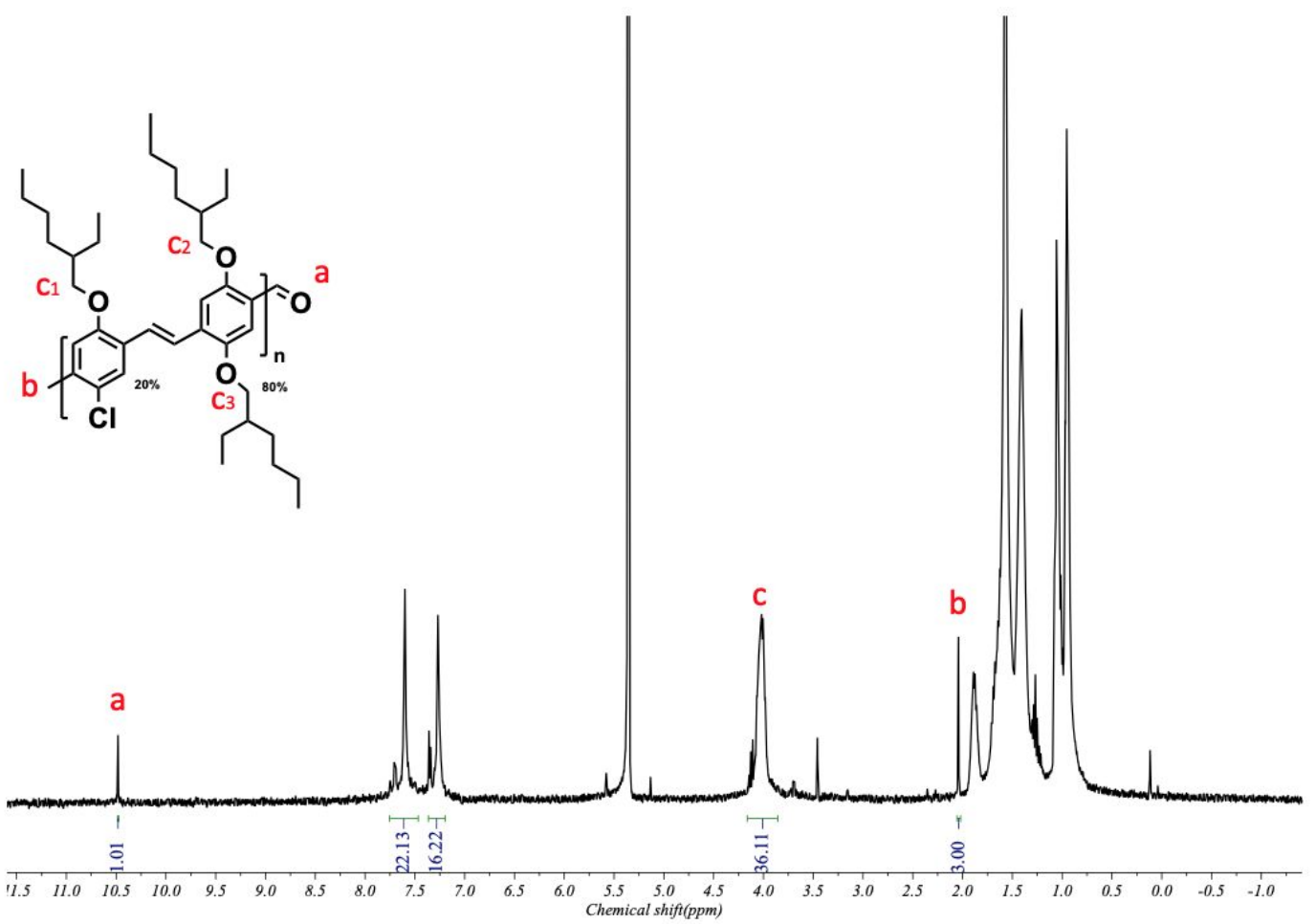

Figure S3 ${ }^{1} \mathrm{H}$ NMR spectrum of $\left(\mathrm{PPV}-\mathrm{Cl}_{20} \%\right)_{10}-\mathrm{CHO}$ in $\mathrm{CDCl}_{3}$. 


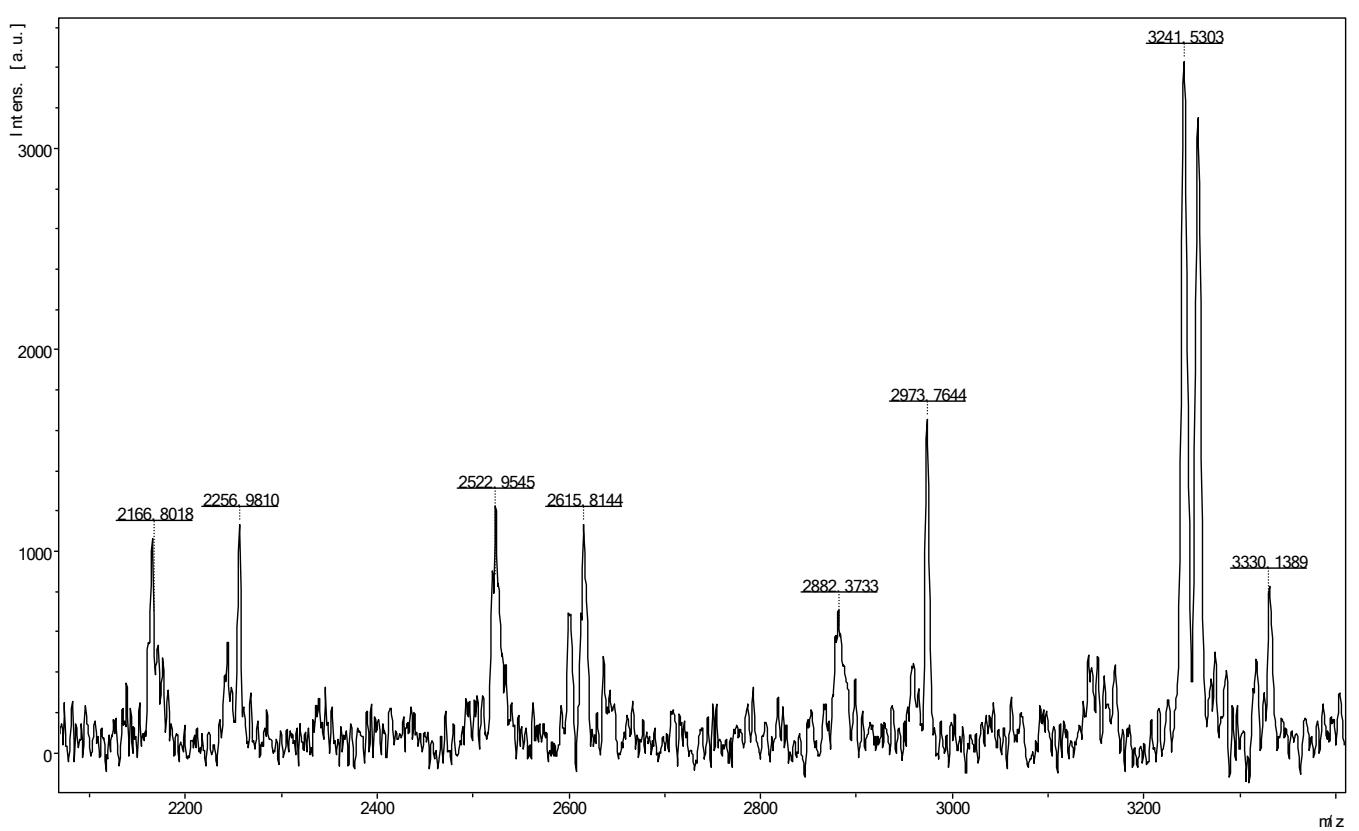

Figure S4 MALDI-TOF mass spectrum of $\left(\mathrm{PPV}-\mathrm{Cl}_{20}{ }\right)_{10}-\mathrm{CHO}$. The EH-PPV repeat unit is $358.2 \mathrm{~m} / \mathrm{z}$ and molecular weight difference of EH-PPV unit and PPV-Cl unit is $94 \mathrm{~m} / \mathrm{z}$.

Table S1 Summary of the data of ${ }^{1} \mathrm{H}$ NMR and GPC of $\left(\mathrm{PPV}-\mathrm{Cl}_{20} \%\right)_{10}-\mathrm{CHO}$.

\begin{tabular}{|c|c|c|c|c|c|c|c|c|}
\hline $\begin{array}{c}\text { (PPV- } \\
\left.\mathrm{Cl}_{20 \%}\right)_{10^{-}} \\
\text {CHO }\end{array}$ & $\mathbf{M}_{\mathbf{n}}$ & PDI & $\begin{array}{c}\text { Integral } \\
\text { of fields } \\
\text { of } \\
\text { aromatic } \\
\text { area in } \\
{ }^{1} \mathbf{H} \text { NMR } \\
\left(\mathbf{I}_{\mathbf{a}}\right)\end{array}$ & $\begin{array}{c}\text { Integral } \\
\text { of fields } \\
\text { of } \\
\text { OCH } \\
\text { in }{ }^{1} \mathbf{H} \\
\text { NMR }^{2} \\
\left(\mathbf{I}_{\mathbf{b}}\right)\end{array}$ & $\begin{array}{c}\text { Number } \\
\text { of PPV- } \\
\text { EH } \\
\text { calculated } \\
\text { by }{ }^{1} \mathbf{H} \\
\text { NMR } \\
\left(\mathbf{n}_{\mathrm{EH}}\right)\end{array}$ & $\begin{array}{c}\text { Number } \\
\text { of PPV-Cl } \\
\text { calculated } \\
\text { by }{ }^{1} \mathbf{H} \\
\text { NMR } \\
\left(\mathbf{n}_{\mathrm{Cl}}\right)\end{array}$ & $\begin{array}{c}\text { Degree of } \\
\text { polymerization } \\
\left(\mathbf{n}_{\mathrm{Cl}}+\mathbf{n}_{\mathrm{EH}}\right)\end{array}$ & $\begin{array}{c}\text { Composition } \\
\text { of PPV-Cl } \\
\left(\mathbf{n}_{\mathrm{Cl}} / \mathbf{n}_{\mathrm{EH}}\right)\end{array}$ \\
\hline & 3430 & 1.12 & 38 & 36 & 8 & 2 & 10 & $20 \%$ \\
\hline
\end{tabular}

$\mathrm{I}_{\mathrm{a}}=4 \mathrm{n}_{\mathrm{EH}}+4 \mathrm{n}_{\mathrm{Cl}}-2$

(Equation S5)

$\mathrm{I}_{\mathrm{b}}=4 \mathrm{n}_{\mathrm{EH}}+2 \mathrm{n}_{\mathrm{Cl}}$

(Equation S6) 


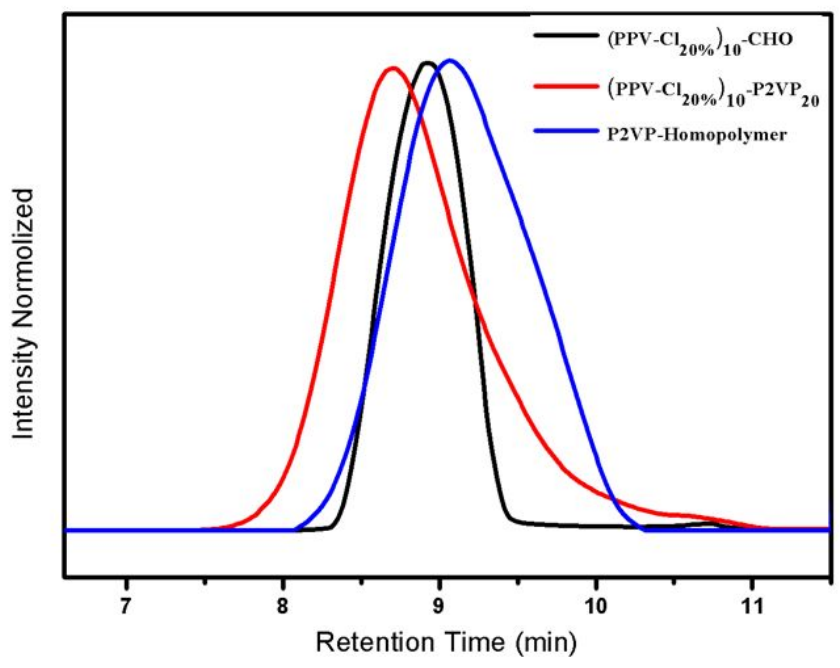

Figure S5 GPC traces (UV-Vis) of (PPV-Cl $20 \%)_{10}-\mathrm{CHO}, \mathrm{P} 2 \mathrm{VP}$ homopolymer and (PPV-Cl $\left.20 \%\right)_{10}-b$ $\mathrm{P}_{2} \mathrm{VP}_{20}$.

Table S2 GPC data of the (PPV-Cl $20 \%)_{10}-\mathrm{CHO}, \mathrm{P} 2 \mathrm{VP}$ and $\left(\mathrm{PPV}-\mathrm{Cl}_{20}\right)_{10}-b-\mathrm{P} 2 \mathrm{VP}_{20}$.

\begin{tabular}{|c|c|c|c|}
\hline BCP & $\mathbf{M}_{\mathbf{n}}$ & $\mathbf{M}_{\mathbf{w}}$ & DPI \\
\hline$\left(\mathbf{P P V}-\mathbf{C l}_{\mathbf{2 0}}\right)_{\mathbf{1 0}}$-CHO & $\mathbf{3 4 0 0}$ & $\mathbf{3 7 4 0}$ & $\mathbf{1 . 1 0}$ \\
\hline $\mathbf{P 2 V P}$ & $\mathbf{2 1 0 0}$ & $\mathbf{2 3 7 3}$ & $\mathbf{1 . 1 3}$ \\
\hline$\left(\mathbf{P P V}-\mathbf{C l}_{\mathbf{2 0} \%}\right)_{\mathbf{1 0}}-\boldsymbol{b}-\mathbf{P} 2 \mathbf{V P}_{\mathbf{2 0}}$ & $\mathbf{5 5 7 7}$ & $\mathbf{6 3 5 8}$ & $\mathbf{1 . 1 4}$ \\
\hline
\end{tabular}

Synthesis of Poly(2,5-di(2'-ethylhexyloxy)-1,4-phenylenevinylene)-block-poly (2-vinylpyridine) (4, PPV-b-P2VP). In a glovebox filled with $\mathrm{N}_{2}, 86.9 \mu \mathrm{L}$ of sec-BuLi (1.3 $\mathrm{M}$ in hexane) was quickly added to a stirring solution of dried $\mathrm{LiCl}(45.7 \mathrm{mg}, 1.13 \mathrm{mmol})$ and 1,1-diphenylethylene (DPE, $20 \mu \mathrm{L}, 0.113$ $\mathrm{mmol})$ in THF $(2 \mathrm{~mL})$ at $-78{ }^{\circ} \mathrm{C}$. Then maintaining $-78{ }^{\circ} \mathrm{C}$, 2-vinylpyridine (2VP) (296.75mg, 2.83 mmol) in THF ( $2 \mathrm{~mL})$ was added to the mixture. After the reaction went on running for $2 \mathrm{~h}$ at $-78{ }^{\circ} \mathrm{C}$, a solution of PPV-Cl ${ }_{20 \%}-\mathrm{CHO}(40 \mathrm{mg}, 0.01 \mathrm{mmol})$ in benzene $(2 \mathrm{~mL})$ was quickly added into the reaction mixture to quench the anion polymerization. Then the reaction temperature was increased to room 
temperature and stirred for additional $12 \mathrm{~h}$. As the reaction stopped, the reaction mixture was poured into $25 \mathrm{~mL}$ chloroform and washed successively with aqueous $\mathrm{HCl}(\mathrm{pH}=3)$, water and aqueous $\mathrm{NaHCO}_{3}$. After rotary evaporating, the crude residue was purified by chromatography (silica gel, eluent was changed from chloroform to chloroform/ $\mathrm{Et}_{3} \mathrm{~N}$ 9:1), and finally red solid (43.6 mg) was obtained. The conversion of $\mathrm{P} 2 \mathrm{VP}$ is $80 \%$. The block ratio of produced $\left(\mathrm{PPV}-\mathrm{Cl}_{20}\right)_{10}-b-\mathrm{P} 2 \mathrm{VP}_{20}$ was determined by NMR.

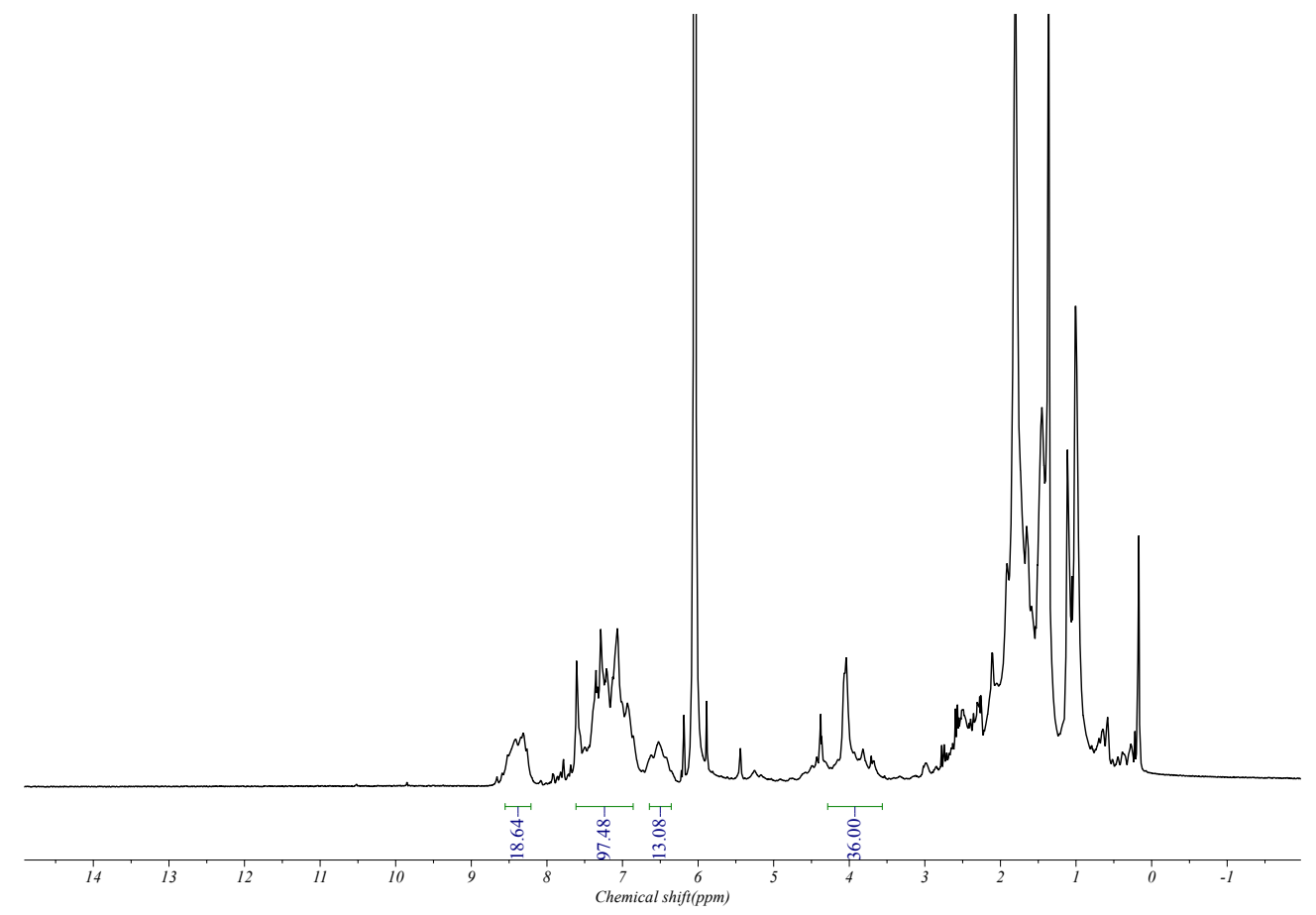

Figure S6 ${ }^{1} \mathrm{H}$ NMR spectrum of $\left(\mathrm{PPV}-\mathrm{Cl}_{20}\right)_{10}-b$-P2 $\mathrm{VP}_{20}$ in $\mathrm{C}_{2} \mathrm{D}_{2} \mathrm{Cl}_{4}$. 

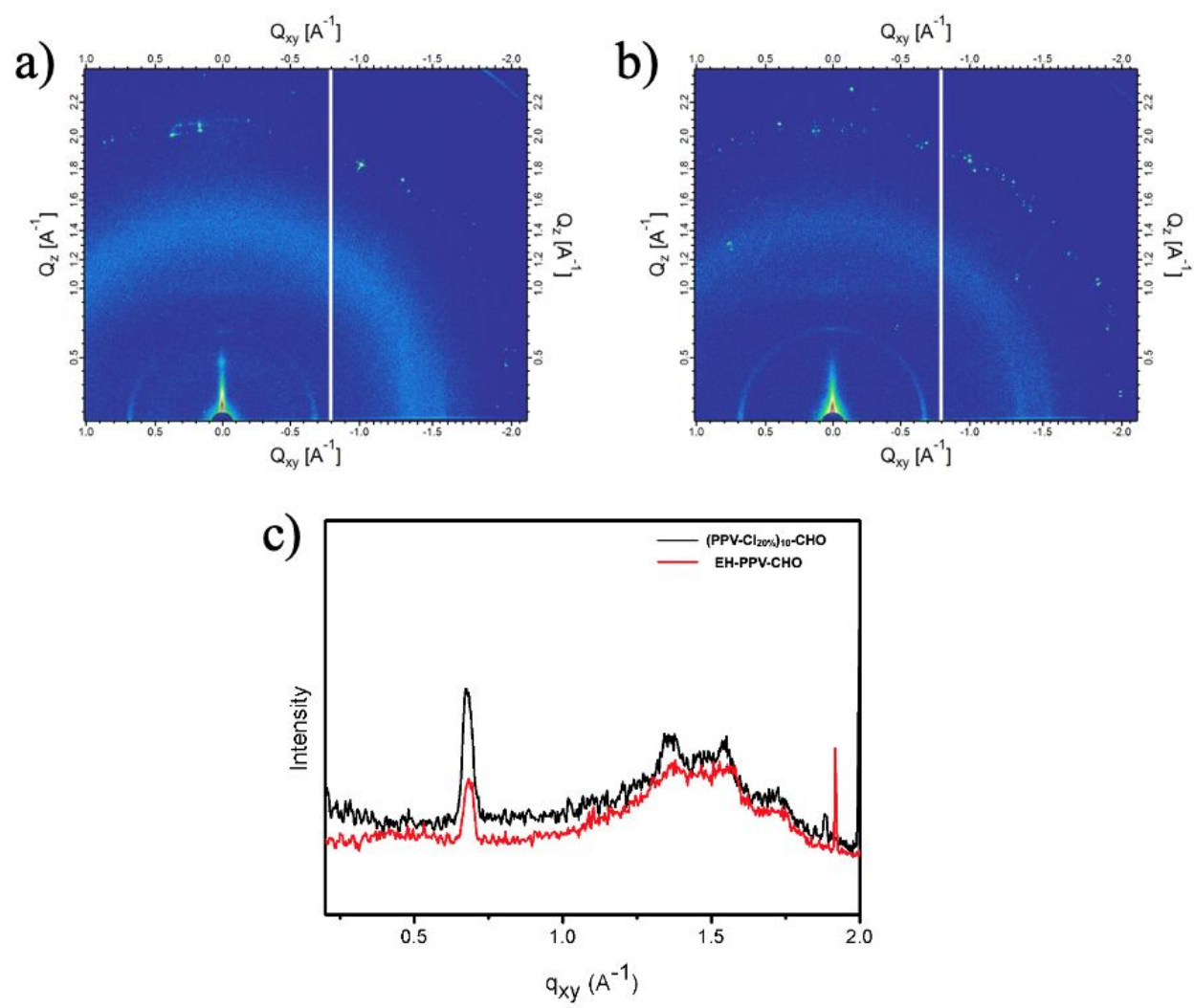

Figure. S7 2D GIWAXS patterns of a. (PPV-Cl $20 \%)_{10}-\mathrm{CHO}$ and b. EH-PPV-CHO. c. GIWAXS profiles along the in-plane direction of (PPV-Cl $20 \%)_{10}-\mathrm{CHO}$ and EH-PPV-CHO.

\section{Supporting Figures and Tables}

Table S3 Summary of the data of the length of the 1D rod-like micelles.

\begin{tabular}{|c|c|c|c|}
\hline Concentration $\left(\mathrm{mg} \mathrm{ml}^{-1}\right)$ & $L_{\mathrm{n}}{ }^{\mathrm{a}}(\mathrm{nm})$ & $L_{w}(\mathrm{~nm})$ & $\boxplus\left(L_{n} / L_{w}\right)$ \\
\hline 0.01 & 6971 & 7528 & 1.08 \\
\hline 0.005 & 3715 & 4161 & 1.12 \\
\hline 0.001 & 1833 & 1929 & 1.05 \\
\hline
\end{tabular}

a100 1D rod-like micelles from TEM images were traced by hand. 

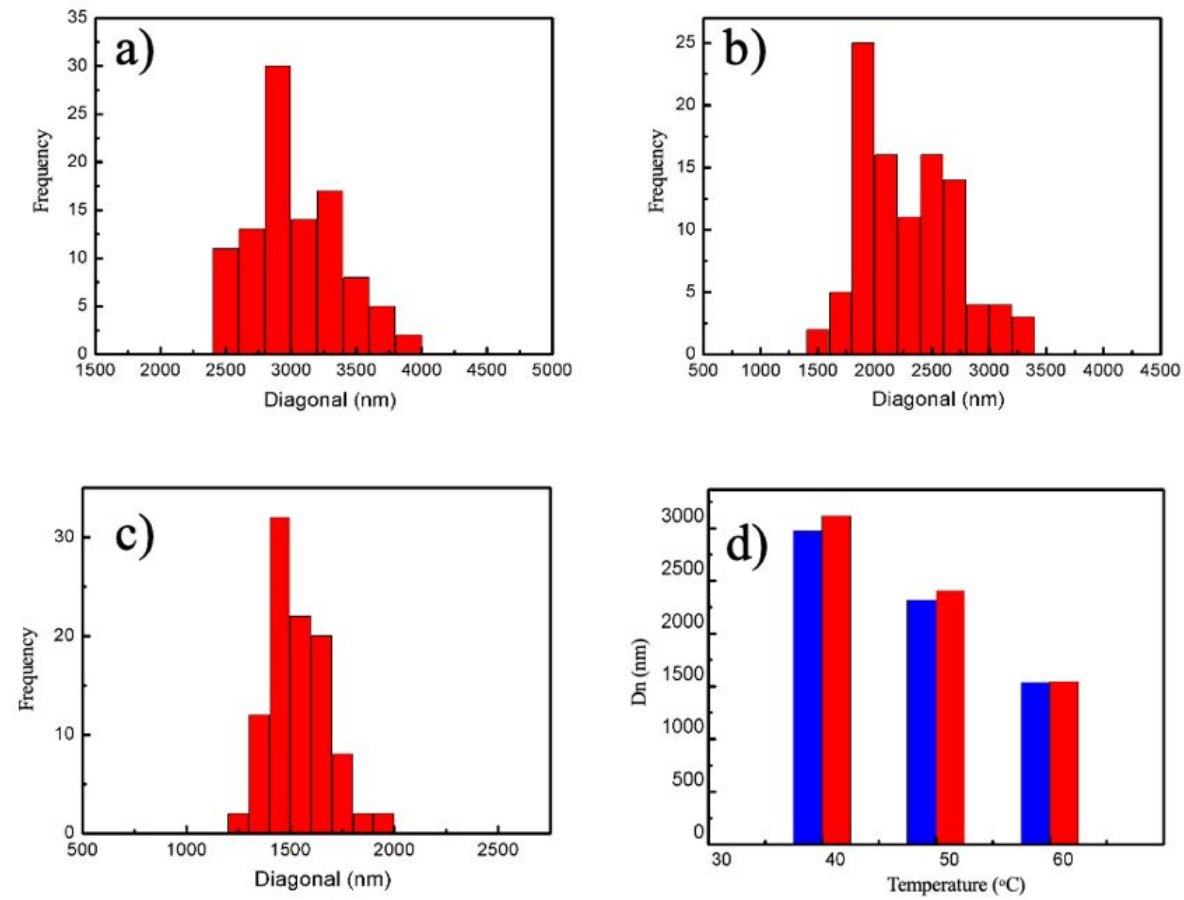

Figure S8 a. b. c contour length distributions of the diagonal length of correspondent 2-D diamond micelles formed at $40{ }^{\circ} \mathrm{C}, 50^{\circ} \mathrm{C}$ and $60{ }^{\circ} \mathrm{C}$; d. $\mathrm{D}_{\ln }$ and $\mathrm{D}_{\text {lw }}$ of diamond micelles formed at $40{ }^{\circ} \mathrm{C}, 50{ }^{\circ} \mathrm{C}$ and $60{ }^{\circ} \mathrm{C}$ (Blue represent $\mathrm{D}_{\mathrm{ln}}$ and red represent $\mathrm{D}_{\mathrm{lw}}$ ).

Table S4 Summary of the data of the scales of the 2D diamond micelles formed at annealing $40{ }^{\circ} \mathrm{C}, 50$ ${ }^{\circ} \mathrm{C}$ and $60^{\circ} \mathrm{C}$.

\begin{tabular}{|c|c|c|c|}
\hline Temperature $\left({ }^{\circ} \mathrm{C}\right)$ & $D_{\ln }{ }^{\mathrm{a}}(\mathrm{nm})$ & $D_{l w}(\mathrm{~nm})$ & $\oplus\left(D_{l n} / D_{l w}\right)$ \\
\hline 40 & 2973 & 3118 & 1.05 \\
\hline 50 & 2316 & 2406 & 1.04 \\
\hline 60 & 1535 & 1548 & 1.01 \\
\hline
\end{tabular}

a100 2D diamond-like micelles from TEM images were traced by hand. 

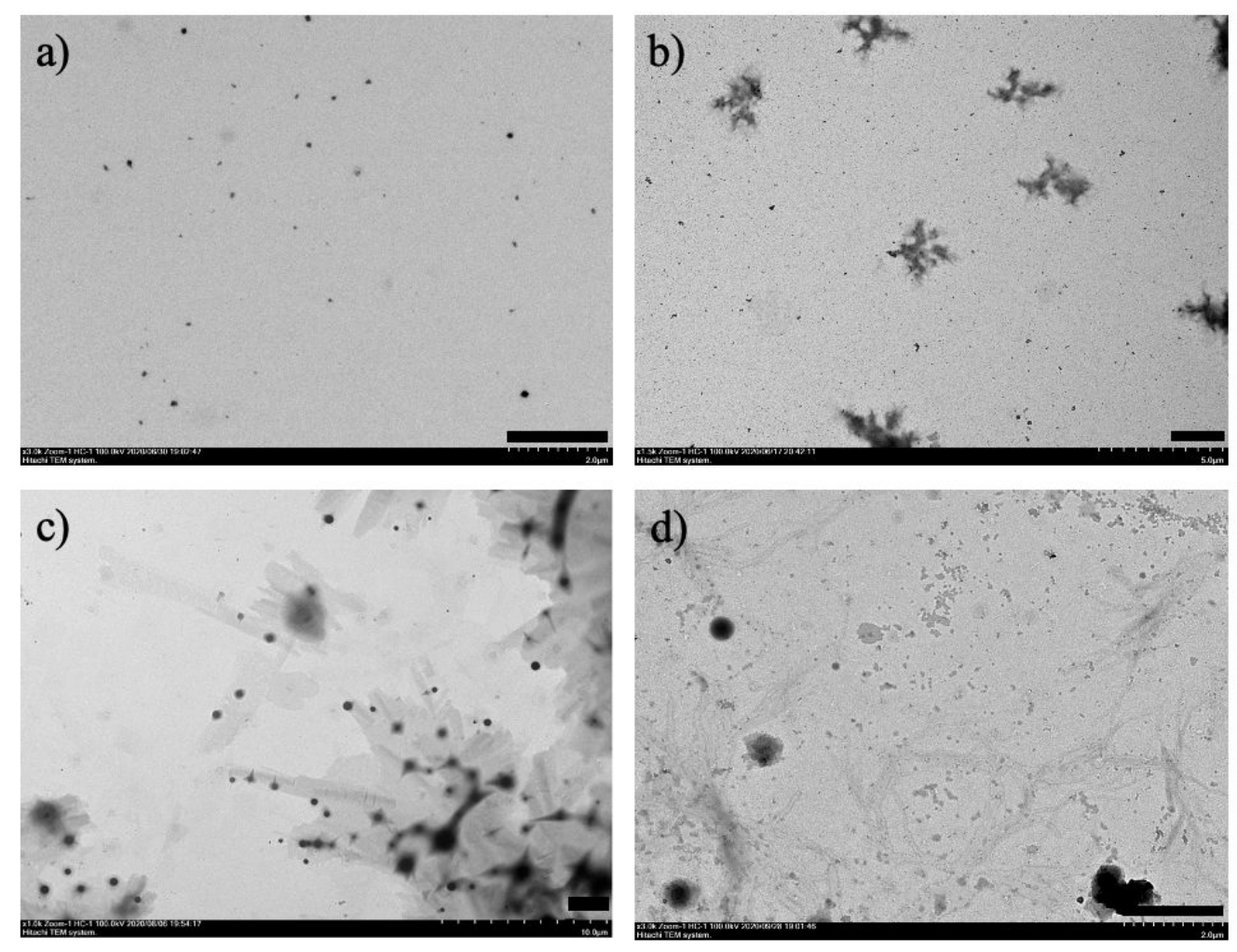

Figure S9 TEM images of the seed micelles and the comparison experiment results. a. TEM images of seed micelles consist of (PPV-Cl $\left.{ }_{20} \%\right)_{10}-b-\mathrm{P} 2 \mathrm{VP}_{20}$ in iso-butanol after the sonication; b. TEM images of contrast experiment using the $\left(\mathrm{PPV}-\mathrm{Cl}_{20}\right)_{10}-b-\mathrm{P} 2 \mathrm{VP}_{20}$ following the same approach without adding unimers for 7 days; c. TEM images of aggregates of polydisperse 2D platelets with poorly defined edges formed by the addition of $10 \mu \mathrm{L}$ of blending unimers to isobutanol at $50^{\circ} \mathrm{C}$ in the absence of seed micelles; d. TEM images of contrast experiment using the (PPV-Cl $\left.l_{20}\right)_{10}-b-\mathrm{P} 2 \mathrm{VP}_{20}$ following the same SA approach without annealing for 7 days. Scale bars in the TEM images are $2 \mu \mathrm{m}$. 

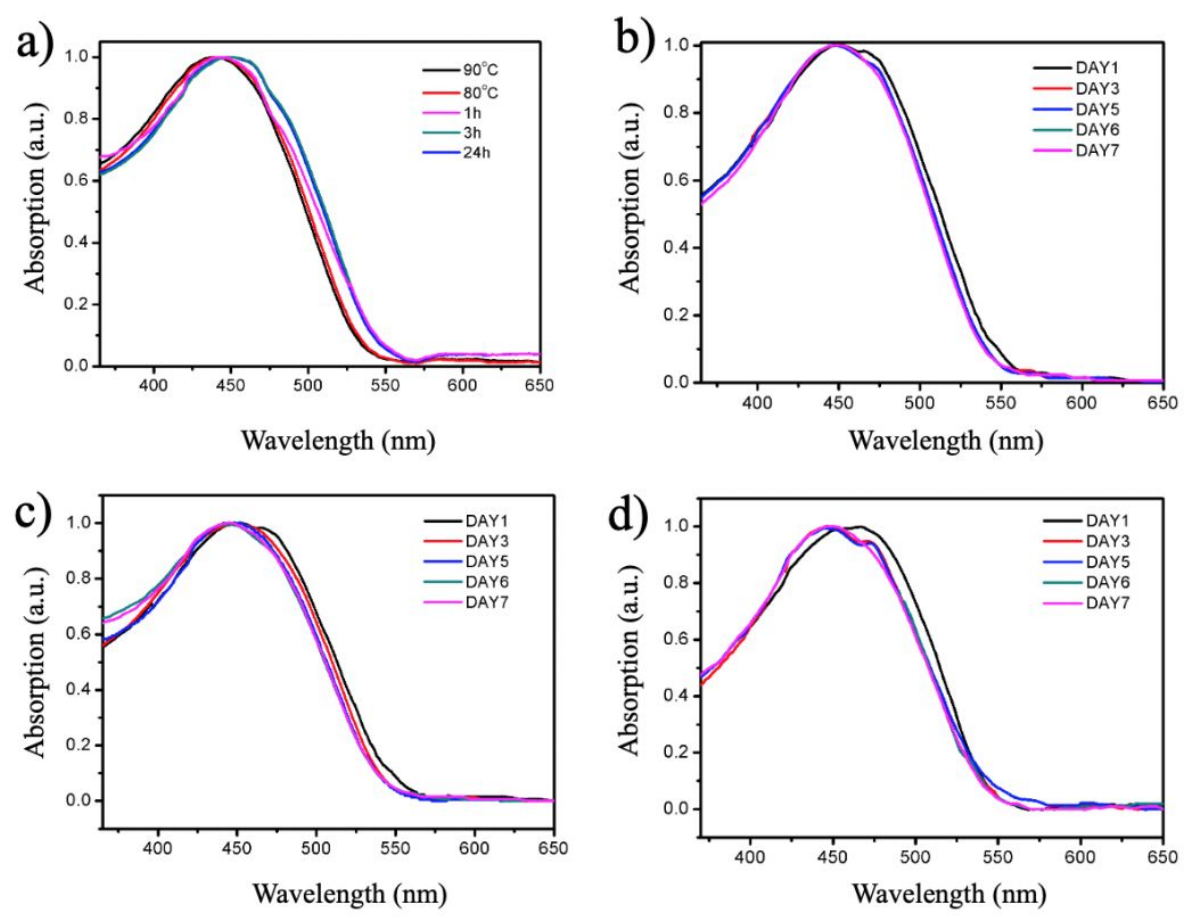

Figure S10 UV-Vis absorption changes of a. 1D rod-like micelles formed from ( $\left.\mathrm{PPV}-\mathrm{Cl}_{20}\right)_{10}-b$ $\mathrm{P}_{2} \mathrm{VP}_{20}$ in $0.01 \mathrm{mg} \mathrm{ml}^{-1}$ isobutanol solution; b. 2D diamond micelles formed from (PPV-Cl $\left.20 \%\right)_{10}-b$ $\mathrm{P} 2 \mathrm{VP}_{20}$ at $40{ }^{\circ} \mathrm{C}$; c. $2 \mathrm{D}$ diamond micelles formed from $\left(\mathrm{PPV}-\mathrm{Cl}_{20}{ }_{2}\right)_{10}-b-\mathrm{P} 2 \mathrm{VP}_{20}$ at $50{ }^{\circ} \mathrm{C}$; d. $2 \mathrm{D}$ diamond micelles formed from $\left(\mathrm{PPV}-\mathrm{Cl}_{20} \%\right)_{10}-b-\mathrm{P} 2 \mathrm{VP}_{20}$ at $60{ }^{\circ} \mathrm{C}$.

a)

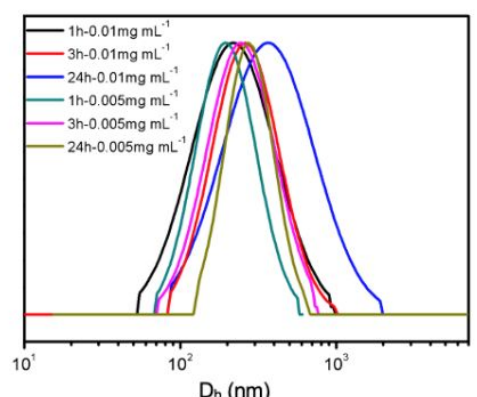

c)

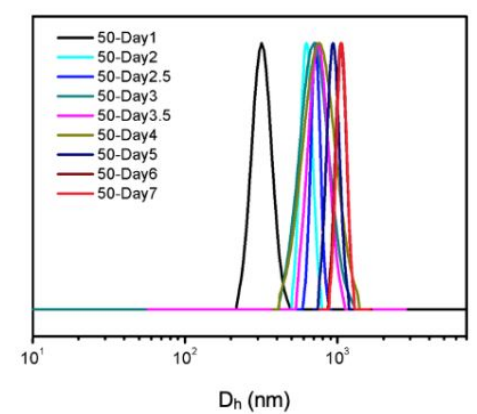

b)

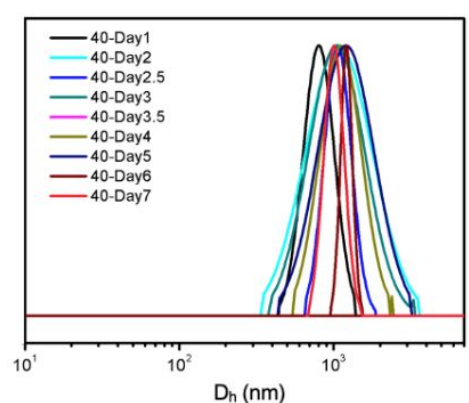

d)

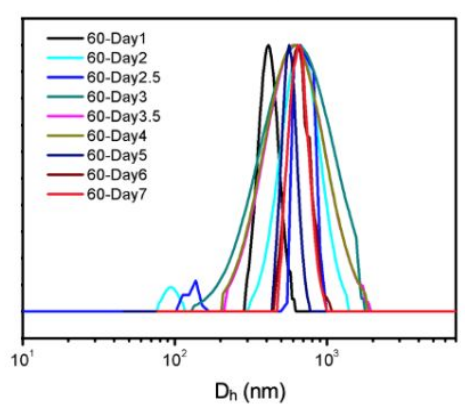

Figure. S11 Changes of hydrodynamic diameter $\left(\mathrm{D}_{\mathrm{h}}\right)$ of PPV-Cl in isobutanol solutions during the aging times. a. 1D rod-like micelles formed from $\left(\mathrm{PPV}-\mathrm{Cl}_{20} \%\right)_{10}-b-\mathrm{P} 2 \mathrm{VP}_{20}$ in $0.01 \mathrm{mg} \mathrm{ml}^{-1}$ isobutanol solution; b. $2 \mathrm{D}$ diamond micelles formed from $\left(\mathrm{PPV}-\mathrm{Cl}_{20} \%\right)_{10}-b-\mathrm{P} 2 \mathrm{VP}_{20}$ annealing at $40{ }^{\circ} \mathrm{C}$; c. $2 \mathrm{D}$ diamond micelles formed from $\left(\mathrm{PPV}-\mathrm{Cl}_{20}\right)_{10}-b-\mathrm{P} 2 \mathrm{VP}_{20}$ annealing at $50{ }^{\circ} \mathrm{C}$; d. $2 \mathrm{D}$ diamond micelles formed from (PPV-Cl $20 \%)_{10}-b-\mathrm{P} 2 \mathrm{VP}_{20}$ annealing at $60{ }^{\circ} \mathrm{C}$. 
Table. S5 Summary of the data of the scales of the 2D diamond micelles formed from different $m_{\text {unimer }} / m_{\text {seed }}$.

\begin{tabular}{|c|c|c|c|}
\hline $\mathbf{m}_{\text {unimer }} / \mathbf{m}_{\text {seed }}$ & $D_{\text {ln }}{ }^{\mathbf{a}}(\mathbf{n m})$ & $D_{\text {lw }}(\mathbf{n m})$ & $\nexists\left(D_{\text {ln }} / D_{\text {lw }}\right)$ \\
\hline 10 & 453 & 462 & 1.02 \\
\hline 25 & 1535 & 1548 & 1.01 \\
\hline 35 & 2306 & 2398 & 1.04 \\
\hline 40 & 2805 & 2858 & 1.02 \\
\hline
\end{tabular}

${ }^{a} 100$ 2D diamond-like micelles from TEM images were traced by hand.

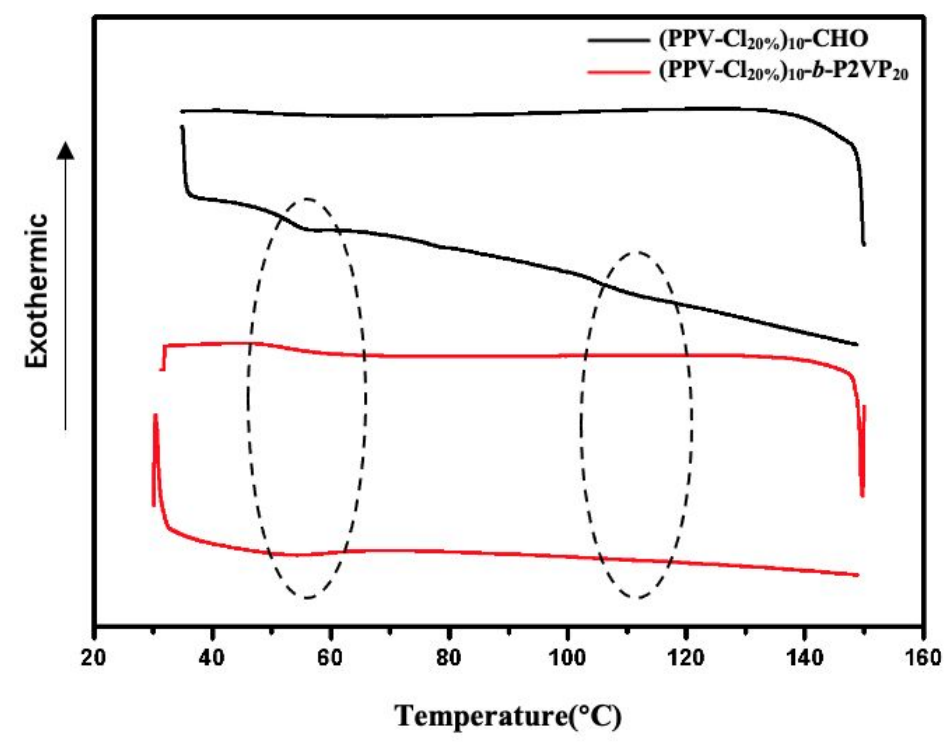

Figure. S12 DSC curves of (PPV-Cl $\left.20_{20}\right)_{10}-\mathrm{CHO}$ and $\left(\mathrm{PPV}-\mathrm{Cl}_{20} \%\right)_{10}-b-\mathrm{P} 2 \mathrm{VP}_{20}$. The measurements were carried under $\mathrm{N}_{2}$ at a heating rate of $10{ }^{\circ} \mathrm{C} \mathrm{min}-1$ for twice scan, and the represented curves are recorded for the second heating scan.

\section{Reference}

(1) L. Han, M. Wang, X. Jia, W. Chen, H. Qian, F. He, Nat. Commun. 2018, 9, 865. 